\title{
«КРИЗИС РАЦИОНАЛЬНОСТИ» В КОНТЕКСТЕ ПРОТИВОСТОЯНИЯ РАЦИОНАЛИЗМА И ИРРАЦИОНАЛИЗМА
}

\begin{abstract}
А.И. Абдула
Основной чертой современной интерпретации проблемы рациональности является выход за рамки рассмотрения этого феномена исключительно как внутринаучной методологической проблемы. Такой подход позволяет выделить различные пласты общественного сознания, которые могут быть охарактеризованы как в той или иной степени «рациональные». Соответственно, подобная реконструкция проводится не только применительно к гуманитарным наукам, искусству, творчеству, но и, с точки зрения исторической преемственности, к религии и мифам, и даже к концепциям, по определению антирационалистическим, таким как экзистенциализм или постмодернизм. При этом сам термин «рациональность» релятивизируется и становится многозначным. «В конце концов, именно Разум включает в себя такие абстрактные чудовища как Обязанность, Долг, Мораль, Истина... Так будь же он проклят!»-пишет в «Очерке анархистской теории познания» П.Фейерабенд, которого считают продолжателем идей школы критического рационализма [12, с. 322]. Приведенная выше эпатажная цитата, характеризует одну из многочисленных версий современного квазирационализма. Здесь можно провести аналогию с выводами Юма, который начинает свои исследования полный надежд прийти к истине, а завершает их скептическим отношением к науке.

Идеи методологического анархизма, подобные тем, что высказывал Феерабенд, не были отброшены; как раз наоборот, они прочно укоренились и сейчас достаточно распространена позиция, в соответствии с которой ставится под сомнение рациональность науки. Быть может, значительная широта охвата рациональностью самых разнообразных сфер человеческой деятельности исторически обусловлена, равно как и ее содер-
\end{abstract}

Актуальні проблеми духовності

(Відп. ред.: Я.В. Шрамко)

Кривий Ріг (2005), 42-52 
жательная релятивность? Или же это своеобразная реакция на претензию всего рационального на научность - реакция, которая зашла слишком далеко и ведет к элиминации самого понятия «рациональность»? Вполне возможно, что некоторые рационалисты, придерживающиеся точки зрения, схожей с взглядами Фейерабенда, надеются, что пересмотр общепринятых подходов и устоявшихся принципов, позволит укрепить позицию разума. Те, кто стоит на более-менее умеренных позициях, указывают на наличие кризиса рациональности, с одной стороны как внутринаучной и внутрифилософской проблемы, а с другой - как способа отношения человека к действительности. Конечно, сетовать на разного рода кризисы старая добрая философская традиция, однако может быть это как раз тот случай когда его наличие не вызывает сомнений?

Советские философы зачастую использовали понятие кризиса, чтобы лишний раз подчеркнуть несостоятельность «буржуазной субъективистской философии» «нео-» и «постпозитивизма», а взгляды «релятивистов» рассматривались как еще одно тому подтверждение. На этом фоне диалектико-материалистическое учение выглядело монолитным и свободным от всяких кризисов. Когда вследствие известных политических преобразований ситуация кардинально изменилась, рациональность принялись «спасать» все теми же методами.

Что же в данном случае подразумевается под «кризисом» рациональности или, другими словами, как аргументируется необходимость описанных выше изменений?

Как правило, в данном контексте выделяют следующие факторы: экологический кризис, который связывают с наукой, а значит и с рациональностью; ограничение свобод и отчуждение человека, которое рассматривают как следствие развития технической рациональности; обезличивание человека, как прямое следствие «рационализации техносферы» и т.п. $[3$, c. 4]. Наряду с этим, ставится под сомнение возможность рациональной реконструкции науки. Казалось бы, все довольно очевидно: констатируется ряд негативных явлений, которые так или иначе связываются с наукой, техникой, а значит и рациональностью (фактор кризисности), что, в свою очередь, непосредственно ведет к решениям в духе Фейерабенда.

По нашему мнению, подобный подход выражает тенденцию, характерную для современной версии иррационализма (эта тенденция типична для противостояния рационализма и иррационализма не только на современном этапе), который стремится распространить свое влияние на философию и науку. В какой степени тот же экологический кризис является следствием позиции разумности? Бесконтрольное использование природных ресурсов и загрязнение окружающей среды стали возможны благодаря развитию науки и техники, - вот основной аргумент. Однако разве основой экологического кризиса не является как раз нерациональ- 
ное (антирациональное) использование достижений научно-технического прогресса? То же касается и социального, экономического кризисов и других негативных явлений, в основе которых, на наш взгляд, лежит как раз отсутствие рационального подхода в тех или иных сферах человеческой деятельности.

Распространена точка зрения, согласно которой, релятивизация способствует более широкому раскрытию содержания понятия, а отсутствие четкого определения, обеспечивает полноту его характеристики. Хотя такой подход и приносит определенные плоды, однако его применение не всегда оказывается целесообразным, и на вопрос о том, можно ли выделить в тех или иных концепциях, независимо от того к какой эпохе они принадлежат, рационалистические или иррационалистические черты, не следует давать однозначно негативный ответ. Применительно к философским концепциям (нас, прежде всего, будут интересовать именно они), речь, несомненно, идет о расширении объема понятия «рациональность», по сравнению с «классическими» аналогами, однако это расширение, на наш взгляд, не должно носить деструктивный характер, который зачастую присущ как современным псевдорационалистам, так и их предшественникам.

На наш взгляд, достаточно эффективным является подход позволяющий сформулировать более строгие и четкие критерии рациональности, которые могут быть эффективно применены, в том числе и к философским концепциям (см., напр., работу Я.В.Шрамко [14] и ссылки к ней). Речь идет о критериях, которые дают возможность представить рациональность в двух аспектах: формальном и содержательном. Формальный аспект характеризует, прежде всего, форму, в которой тот или иной философ излагает свои взгляды, насколько последовательны, связанны и аргументированы его вербально-логические построения. Содержательная составляющая характеризует ту роль, которая отводится в данной философской системе разуму, будь то гносеологический, онтологический или любой другой его аспект.

Если пользоваться данными критериями, то представляется возможным достаточно однозначно указать в каждом конкретном случае ряд рационалистических и антирационалистических черт. При таком подходе представляется возможность выделить аспекты рационального и иррационального на протяжении всей истории философии. На наш взгляд, для каждого из этих направлений характерна определенная историческая преемственность, каждое из них характеризуется специфическими чертами. Для иррационализма это, прежде всего, глубокие мистические традиции, уверенность в том, что высшее знание (или знание о высшем) недостижимо, если речь идеи о средствах «слабого» разума. Однако, даже система, направленная на утверждение авторитарности разума может 
быть по отношению к формальному аспекту иррациональной. Использование формального и содержательного критериев позволяет перейти от рассмотрения локальных кризисных явлений, к выявлению закономерностей, с которыми связано преобладание того или иного подхода (можно говорить о социальной обусловленности такого преобладания).

Естественно, возникает вопрос о том, какие требования должны быть предъявлены к форме изложения и должны ли они быть предъявлены вообще. С нашей точки зрения, применение формального критерия достаточно целесообразно, так как в определенном смысле именно формальная составляющая имеет решающее значение. Конечно, следует помнить о провале «жестких» требований, предъявленых неопозитивистами (например, требование соответствия атомарных высказываний эмпирическим «фактам»-см., например, работу Карнапа [2]). Однако требования непротиворечивости, логической замкнутости и определенности основных понятий не носят жесткий и категорический характер и вполне могут и должны быть применимы к философским концепциям.

Требование непротиворечивости достаточно самоочевидно. Наличие логических противоречий в рассуждениях, на наш взгляд является признаком нездорового состояния теории, и может свидетельствовать о ее спекулятивном характере. Кроме того, с прагматической (практической) точки зрения, такая концепция непродуктивна и несостоятельна.

Принятие логических следствий обязывает субъекта «соглашаться» со всеми логическими следствиями в процессе своих рассуждений. Если данное требование не соблюдается, то концепция так же считается нерациональной.

Требование определенности основных понятий (терминов), накладывает минимальные ограничения. Каждое новое понятие, (а такими зачастую изобилуют иррационалистические концепции) должно быть определено через другие, общепринятые понятия. По крайней мере, субъект должен указать основания своих рассуждений (скажем, интуитивно очевидньг постулатов). Следует отметить, что этот принцип не должен абсолютизироваться, во избежание регресса в бесконечность. Ясно, что лишь немногие работы полностью соответствуют данным критериям. Следует также учитывать, что приведенные критерии - не более чем «идеальные» ориентиры, соответствие которым обеспечивает формальную рациональность изложения.

Естественно, при таком подходе, позиции значительного числа философов могут быть расценены как формально иррационалистические. Однако с другой стороны, например, позиция Д. Юма, при рассмотрении с этой точки зрения гораздо более рациональна, чем скажем, концепции большинства немецких классиков.

Идеи параллельного развития, противодействия и взаимодействия ра- 
ционализма и иррационализма и подобные им, можно встретить в работах целого ряда философов. Б. Рассел в «Истории западной философии» [8], довольно часто подчеркивает, в какой степени, тот или иной философ может быть назван «ученым». Он использует, однако, несколько иные критерии, уделяя значительное внимание методу, тем не менее, наша позиция в этом вопросе сходна с позицией Рассела. Что же касается непосредственно содержательной составляющей и той роли, которая отводится разуму, то здесь реконструкция проводилась и ранее, причем в последнее время этой проблемой занимаются как отечественные, так и российские философы (см. например, статью К.В. Рутманиса [10], в которой проводятся параллели между понятиями Логоса в Античности и современной интерпретацией категории Разума).

Здесь имеет смысл вспомнить и предложенную П.Сорокиным типологию ценностных суперсистем (см. [11]), в основу которой он положил критерии превалирующего представления о природе бытия, основных потребностей человека, степени их реализации и методов удовлетворения, выделив таким образом два культурологических типа: чувственный (сенситивный) и умозрительный (идеациональный). Чувственный менталитет признает чувственную реальность, отрицая сверхчувствительную реальность, характеризуется потребностями и целями физической природы. Способ их реализации - изменение окружающего, «внешнего» мира. Идеациональный менталитет, воспринимает реальность как нечто внечувственное и внематериальное, ценности носят духовный характер, физические потребности минимизируются. На основе двух чистых типов формируется смешанный тип. С помощью указанной типологии осуществляется периодизация исторического процесса - выделяются периоды доминирования чувственной и умозрительной культур. В тоже время, на современном этапе достаточно распространенной является точка зрения, согласно которой вся история современной философии в значительной степени опосредована концепциями Платона и Аристотеля и характеризуется преобладанием влияния одного из этих мыслителей на том или ином историческом этапе.

В.В.Шкода во вступительной статье к [6, с.3] отмечает: «Не будет, повидимому, большим преувеличением сказать, что в европейской интеллектуальной истории чередуются только эпоха Платона и эпоха Аристотеля». Схожей точки зрения придерживается В.И. Россман в статье «Платон в зазеркалье русской идеи» (см. [9]). Он обращает внимание на то, что развитие западной цивилизации во многом опосредовано влиянием Аристотеля, в то время, как Восток, вследствие целого ряда причин так и не смог отказаться от идей платонизма. На наш взгляд, здесь в достаточной степени, допустимы аналогии между идеями мистицизма и взглядами Платона с одной стороны, требованиями «научности» и подходом 
Аристотеля - с другой. Фактически речь идет все о том же противостоянии рационалистической и иррационалистической тенденций, каждая из которых характеризуется своего рода преемственностью.

$\mathrm{C}$ нашей точки зрения, апелляции к различного рода кризисам можно интерпретировать как своеобразную уловку иррационализма, имеющую конечной целью подорвать авторитет разума и науки. В этой связи, имеет смысл, хотя бы в самой общей форме, выделить основные этапы противоборства двух направлений, рассмотрев его на ряде конкретных примеров.

Началом иррационалистической традиции в философии принято считать культ фракийского бога плодородия Диониса или Вакха, который затем укоренился и в Греции, как протест против «общественного благоразумия», и ограничивающего влияния цивилизации. Б. Рассел в «Истории западной философии», причины распространения культа Вакха связывает, прежде всего, с географическим положением - соседство с Фракией, гораздо менее цивилизованной, чем Греция (с эти связан тот факт, что культ содержал значительные варварские элементы). Кроме того, по мнению Рассела, благодаря тому, что греки «достаточно быстро пришли к цивилизации», они в определенной степени были склонны скорее к «инстинктивному и полному страстей образу жизни, нежели тому, который предписывала им ходячая мораль» [8, с.32]. Жрецы или посвященные, находясь в состоянии алкогольного опьянения, впадали в «божественное безумие» в котором, как они считали, им открывались «высшие истины». Культ Вакха протерпел с течением времени изменения и, будучи опосредован учением Орфея, оказал существенное влияние на философов античности. Орфики пытались при помощи «очищения» достичь полного духовного слияния с Вакхом. «Среди греческих, как и среди позднейших философов» - пишет Рассел, - «некоторые тяготели к науке, другие к религии, последние прямо или косвенно многим обязаны религии Вакха. Особенно это относится к Платону, а через него это влияние распространилось на те более поздние движения мысли, которые, в конце концов, воплотились в христианской теологии» $[8$, с. 33-34].

В противоположность мистической традиции, достаточно быстро распространившейся сначала в Аттике, а затем и в Южной Италии и Сицилии, в Милете существовала философская школа, достижения и искания которой в значительной степени отличались от философских направлений, подверженных влиянию мистицизма. Представителей милетской школы - Анаксимена, Анаксимандра и Фалеса, можно в той степени назвать представителями рационалистического направления в философии, в какой они отдавали предпочтение исследованию окружающего мира и его первооснов, скорее посредством гипотез, чем орфического откровения. Культ Вакха и Орфея практически не затронул Милет, длительное время сохранявший «олимпийскую» религиозную ориентацию, которая 
носила, в основном, показной характер.

Как видим, ранний этап развития философии, уже содержал в себе элементы, которые можно назвать прообразами современных рационалистических и иррационалистических систем. С одной стороны - это культ Вакха и различные его интерпретации, ориентированные на получение высшего знания «внеразумным» путем, с другой - традиция «первых философов» ориентированная на познание мира с помощью разума. Дальнейшее развитие философской мысли обостряет конфронтацию между двумя направлениями, делая ее более открытой.

Следующий, достаточно показательный этап - своеобразная полемика по основным философским проблемам двух наиболее выдающихся философов античности Платона и Аристотеля. Следует, однако, сразу оговориться, что и тот и другой подчеркивали значимость разума, считая его важным для познания. Тем не менее, разум у Платона и разум у Аристотеля - понятия различные. Разум Аристотеля - это скорее, мышление ученого, в основе его - использование логики, наблюдений и фактов. Разум Платона - разум диалектический, через него, в интеллектуальном откровении лежит путь в мир абсолютных истин - Платоновских эйдосов, которые сродни мистическим числам Пифагора. В то же время отличается и форма, которую используют Платон и Аристотель для своих произведений. Платон - больше склонен к диалогизированному, поэтическому изложению. Его нельзя обвинить в отсутствии четкости и аргументированности, и тем не менее, сухой «практик» Аристотель гораздо ближе по форме и стилю к современному ученому.

Платон рационалист скорее формальный, чем содержательный, хотя не следует забывать, что и Аристотель - не чистый «рационалист», хотя бы потому, что он в значительной степени подвержен влиянию Платона, и в его философии достаточно спекулятивных и авторитарных идей. Карл Поппер, например, вообще не считает Аристотеля, в отличии от Платона, выдающимся философом, критикуя его за его склонность к «бесполезной» систематизации и энциклопедичности.(см. [7]) Аристотель и Платон - рационалисты, но те иррациональные элементы, которые содержались в их концепциях были впоследствии разработаны и использованы теми, кто называл себя их последователями.

$\mathrm{C}$ нашей точки зрения, было бы наиболее целесообразно противопоставить Платона и Аристотеля не друг другу, а скорее представителям неоплатонизма, например, Плотину, которые, являясь источником многих идей средневековой христианской философии, как раз использовали иррационалистические элементы концепций обоих философов. Рассел указывает, что идеализм Плотина напрямую связан с тяжелым экономическим и социально-политическим положением, в котором оказался Рим в 3 -м веке н.э. «Он отвернулся от зрелища разорения и нищеты в реальном 
мире, чтобы созерцать вечный мир блага и красоты. В этом он находится в согласии со всеми наиболее серьезными людьми своего века. Для всех них - и христиан и язычников - мир практических дел одинаково кажется не дающим надежды и только ,иной мир“ представляется достойным преданности». [8, с. 333]. Плотин развивает метафизическую часть теории эйдосов Платона, которая приобретает у него четко выраженный мистический характер Характерно, что разочарование в реальности и разуме практически всегда связано с теми или иными социальными катаклизмами, будь то проблемы в экономике, экологии или военные конфликты.

В противоположность неоплатоникам, примером более-менее последовательной рационалистической позиции в античной философии может служить философия атомистов. Рассел указывает, что «Точка зрения Левкиппа и Демокрита удивительно похожа на точку зрения современной науки и лишена большинства тех недостатков, которым склонна греческая спекулятивная мысль» [8, с. 87]. Здесь будет уместно, на наш взгляд, упомянуть и Эпикура. Несмотря на то, что Демокрита и Эпикура достаточно часто противопоставляют друг другу, (в частности, Асмус, ссылаясь на Маркса, указывает, что цель философии Эпикура - не познание само по себе, а просвещение людей), и то, что до наших дней дошла лишь незначительная часть произведений последнего, мы можем назвать философию Эпикура в значительной степени рационалистической [1, с. 318]. По Эпикуру, философия - практическое учение, необходимое для того, чтобы дать людям счастливую и безмятежную жизнь. Достижению этой цели и должно служить изучение природных законов и явлений - физика, которая в свою очередь основывается на теории познания - канонике. Для достижения поставленной цели Эпикур предлагает избавиться от «неразумной веры» и «необоснованных мнений» и изучать явления природы, дав каждому из них несколько различных объяснений, не противоречащих фактам наблюдений. Подобный подход можно сравнить с достаточно распространенной в наши дни плюралистической установкой относительно возможных подходов к рассмотрению философских проблем. При этом «наблюдения» Эпикура в некоторых случаях давали результат, вполне созвучный с результатами исследований современной науки.

Противостояние «рационализма» и «иррационализма» в средневековой философии, это - противостояние двух подходов к обоснованию Христианской истины - безоговорочного ее принятия или принятия на основе разумного и критического осмысления. Достаточно очевидно, на наш взгляд, что «непосредственная данность» истины-веский аргумент в пользу того, чтобы указать в лучшем случае на формальное использования термина «рациональность». Тем не менее, «рационалистическая методологическая установка», возникшая в процессе схоластических диспутов, - чуть ли не единственная возможность разума в условиях религи- 
озного догматизма, длившегося на протяжении десятков веков, проявить себя, и ее использование оказало значительное влияние на дальнейшее развитие философии. Позицию религиозного формального «рационализма», отстаивал, в частности П. Абеляр. Естественно, идеи разумного обоснования веры не были позитивно восприняты ортодоксальными служителями церкви. Абеляр был вынужден отречься от своих, получивших широкое распространение взглядов, которые впоследствии были объявлены еретическими. В изучении доктрин веры Абеляр опирался на диалектический метод лингвистической интерпретации, разработка которого может считаться его значительным достижением, настаивал на необходимости поиска собственных объяснений и решений, пути к постижению истины (см. [5]).

Возрождение, а затем и философия Нового времени - это путь к постепенному укреплению влияния разума и провозглашения его основой познания. Декарт, Локк и Бэкон сделали достаточно для того, чтобы научно-рационалистический подход, занял особое положение на протяжении последующих столетий.

Начиная с Нового времени, противостояние двух подходов носило ярко выраженный характер. Тем не менее-утверждение о первичности разума в познавательном процессе - не единственное условие для того, чтобы называть философа в полной мере рационалистом. На этом фоне достаточно показательно противоборство философских систем Гегеля и Шопенгауэра, которое к тому же подогревалось их личной неприязнью. Гегель постулировал доминирующую роль мирового Разума, но что это был за разум? Был ли это разум в понимании Аристотеля или Декарта? Отнюдь. Казалось бы, иррационалист, Шопенгауэр резко критикует (зачастую достаточно обоснованно) Гегеля за спекулятивность и надуманность его философии и противопоставляет ей собственную, но достаточно четкую и аргументированную. В некоторых своих работах, (особенно ранних) [13], Шопенгауэр настолько последователен, что его можно назвать чуть ли одним из наиболее рациональных философов, если исходить из формы изложения и аргументации. Что касается непосредственно содержания, то работа «О четверояком корне...»- это скорее работа рационалиста картезианского образца, чем «врага разума». Философию Гегеля Шопенгауэр называет бессмысленной, и обвиняет его в том, что он «водит немцев за нос». И в этом Шопенгауэр не одинок. Карл Поппер также резко негативно высказывается о философском стиле Гегеля (см. [7]). Как и Шопенгауэр, он считает, что философствование Гегеля зачастую сводится к «набору бессмысленных словосочетаний», а ее цель-всеми возможными средствами обосновать «совершенство» прусской монархии. При этом, Поппер указывает на непосредственную взаимосвязь между идеями Платона, Гераклита и Гегеля. 
Следы влияния культа Вакха прослеживаются и в значительно более поздние периоды. В. Менжулин в книге «Расколдовывая Юнга» пишет следующее: «...Ницше и Юнг-со своим увлечением то ли дионисийством, то ли вотанизмом оказались, хотели они того или нет, важными персонажами спекуляций внутри и вокруг ... идеологии национал-социализма». Там же Менжулин цитирует Пола Бишопа, автора книги «Дионисийская самость: Юнговская рецепция Фридриха Ницше»: «Важно осознать, насколько тесно они (и Ницше и Юнг) были связаны с романтическим проектом новой-дионисийской мифологии. Оба почерпнули свои познания в классической мифологии из одних и тех же академических источников» $[4$, с.41]. Проведенный В. Менжулиным детальный анализ показывает, что основные элементы концепции Юнга спекулятивны (как раз настолько, чтобы согласно формальному и содержательному критериям усомниться в научной ценности его трудов).

Ограничиваясь в рамках данной статьи рядом приведенных примеров, отметим, что исчерпывающее исследование с использованием предложенных критериев позволит, на наш взгляд, получить достаточно полную характеристику как конкретных философских учений, так и рационалистической и иррационалистической систем в целом, и выделить определенную преемственность в их развитии (в случае иррационализма речь может идти о наследовании традиций вакхического культа).

Применение данного подхода может выступить в роли альтернативы «конформистским» концепциям, в основе которых лежат представления о кризисном состоянии рационализма во всех его аспектах, по сути являющиеся аргументом иррационализма в пользу укрепления своих позиций, и связанного с этим постулирования равнозначной или даже преобладающей роли иррациональных факторов.

\section{1 Литература}

[1] Acмус В.Ф. Античная философия. - М.: Высшая школа, 2003.

[2] Kapнan P. Преодоление метафизики логическим анализом языка // Вестник Московского университета. Серия 7, Философия, №6, 1993. - C. 11-26.

[3] Исторические типы рациональности.-Т.1 / ИФ РАН; отв. ред. В.А.Лекторский. - М., 1995.

[4] Менжулин В. Расколдовывая Юнга: от апологетики к критике. - K.: Cфера, 2002. 
[5] Мудрагей Н.C. Рациональное и иррациональное в средневековой теории познания философии // Рациональность как предмет философского исследования / ИФ РАН; под ред. Н.В. Ветровой. - М., 1995.

[6] Мыслители Греции: от мифа к логике.-М.: ЭКСМО-Пресс; Харьков: Фолио, 1999.

[7] Поппер К.Р. Открытое общество и его враги: Пер. с англ.-М.: Феникс, 1992.

[8] Рассел Б. История западной философии. - Ростов н/Д: Феникс, 2002.

[9] Россман В.И. Платон в зазеркалье русской идеи // Актуальні проблеми духовності. Вип. 4(1).-Кривий Ріг: Вид-во «I.В.I.», 2004.C. $111-124$.

[10] Рутманис K.В. Генезис идей рациональности в философии // Рациональность как предмет философского исследования / ИФ РАН; под ред. Н.В. Ветровой. - М., 1995.

[11] Сорокин П. Социальная и культурная динамика. Исследование изменений в больших системах искусства, истины, этики, права, и социальных отношений // Вестник Московского университета. Серия 7 , Философия, №1, 1993.

[12] Фейерабенд П. Избранные труды по методологии науки: Пер. с англ.-М.: Прогресс, 1986.

[13] Шопенгауэр А. О четверояком корне закона достаточного основания...- М.: Наука, 1993.

[14] Шрамко Я.В. Логико-эпистемологические предпосылки развития знания // Актуальні проблеми духовності. Вип. 4(1). - Кривий Ріг: Вид-во «I.В.І.», 2004.- С. 151-162. 